\title{
Myiasis in an urban setting: A case report
}

\author{
Gerry Predy MD, Mary Angus RN, Lance Honish CPHI(C), Charles E Burnett MB ChB, Andrew Stagg MD
}

\author{
G Predy, M Angus, L Honish, CE Burnett, A Stagg. Myiasis in \\ an urban setting: A case report. Can J Infect Dis \\ 2004;15(1):51-52.
}

Myiasis is considered to be a condition only found in tropical, developing countries. However, this paper reports a case identified in an urban, North American setting. The clinical presentation is discussed along with the underlying comorbidities and social determinants.

\section{Myiase en milieu urbain : exposé de cas}

La myiase est considérée comme une affection typique des pays tropicaux en développement. Toutefois, voici un cas de myiase observé en milieu urbain, en Amérique du Nord. Il sera question, dans le présent article, du tableau clinique ainsi que des affections concomitantes sous-jacentes et des déterminants sociaux.

Key Words: HIV; Homelessness; Maggots; Myiasis; Vaginal

\section{CASE PRESENTATION}

A 36-year-old woman was seen in a local emergency department with a two-day history of pain and irritation in the genital area. Initial examination revealed edema and crusting of the vagina and excoriation to both the vulva and perineum. Speculum examination was limited due to pain; however, a maggot was found on the vulva. A gynecological consultation was obtained and because of the pain and uncertain diagnosis, the patient was admitted and an examination was performed under general anesthetic. There was a strong putrid smell of anaerobes and a purulent discharge coming from the cervix; the vulva and perivulvar skin were superficially excoriated with some crusty superficial lesions, and two vigorous wormlike organisms, each approximately $1 \mathrm{~cm}$ long, were present in the vulva. No other infestation was noted. There was no evidence of Bartholin gland infection and the worm-like organisms were caught and sent for identification. Swabs were taken from the vulva, vagina and cervix. The vulva and vagina were cleaned with Betadine (Purdue Pharma, Ontario) and gentian violet was applied. The patient discharged herself from the hospital against medical advice after the procedure.

The pathologist identified the worms as maggots (Figure 1), each measuring 1 to $2 \mathrm{~cm}$. Unfortunately, the maggots were not sent for species identification. The cultures grew mixed flora and no sexually transmitted organisms were identified. The patient had a mild anemia (hemoglobin of $96 \mathrm{~g} / \mathrm{L}$ ), thrombocytopenia (platelets $116 \times 10^{9} / \mathrm{L}$ ), and elevated alkaline phosphatase $(143 \mathrm{U} / \mathrm{L})$ and aspartate aminotransferase (47 U/L). During the two-day hospital stay, the patient was also tested for HIV and hepatitis C. The test results were both positive and were reported to the Medical Officer of Health 10 days after the test. Public health follow-up was then initiated. Unfortunately, the patient was lost to follow-up because she had no fixed address. She was found almost one and a half months later in a detoxification unit at a local shelter. She was immediately referred to a community health clinic to see a physician for follow-up HIV care.

Upon interview by a public health nurse, it was noted that the patient had spent approximately the last 10 years living on the streets or in abandoned housing and shelters. Just before her hospitalization, she spent a month living outdoors. During this one-month period, she did not bathe, change or wash her clothes. Her usual habit was to obtain fresh clothing from a local emergency relief centre every week where she would also shower; however, she did not access the centre during the month she lived outdoors. The patient admitted to consuming both beverage and nonbeverage alcohol, panhandling for money, and relying on handouts from strangers to obtain food.

Because the patient had discharged herself from the hospital, medical staff were unable to discuss diagnoses or provide discharge teaching so she was unaware of her HIV status or myiasis. She was informed and counselled on both diagnoses and was accepting of her HIV diagnosis but was quite distraught about the presence of maggots. She did not show up for her follow-up medical appointment to the community health clinic but returned seven months later for an HIV work-up. There has not been a repeat visit for follow-up care since and it is not known if she accessed routine medical care at other clinics.

\section{DISCUSSION}

Maggots are the larvae of flies. Human infestation (myiasis) occurs when flies lay new eggs on the skin or in wounds. Myiasis can be classified according to site of infestation (1). Cutaneous is the most common form but nasopharyngeal, ophthalmic, intestinal and urogenital infestations have been reported.

Public Health Division, Capital Health, Edmonton, Alberta

Correspondence: Lavera Sebulsky, Public Health Division, Capital Health, 300, 10216 - 124 Street, Edmonton, Alberta T5N 4 A3.

Telephone 780-413-7946, fax 780-413-7950

Received for publication August 28, 2003. Accepted December 29, 2003 


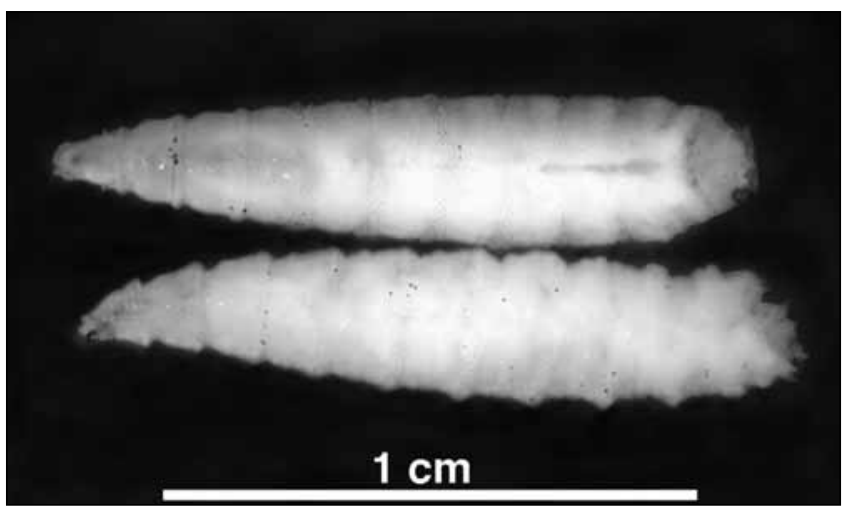

Figure 1) Maggot - Protophormia terraenovae Robineau-Desvoidy. Photograph provided by Danny Shpeley, BSc, Assistant Curator, EH Strickland Entomological Museum, University of Alberta, Edmonton, Alberta

Maggots can enter through intact skin (more commonly in tropical countries) or through a wound. They may also enter a body orifice without tissue invasion. This has been termed pseudomyiasis (2). The patient presented in this case did exhibit excoriation of the vulva with clinical evidence of invasion (swelling) so we consider her to be a case of myiasis.

Greenberg (3) identified the following four risk factors or indicators for infestation:

- Helpless or debilitated person;

- Bleeding or odours of decomposition present;

- Summer season; and

- Neglect in nursing care.

In this case, the first three factors were present.

A multicentre, prospective, observational study of American urban and suburban patients who were infected with maggots was recently conducted (4). Forty-two cases of American myiasis were identified. The male to female ratio was $5.5: 1$ and at least $16(38 \%)$ of the patients were homeless. Sherman (4) also conducted a literature review and found that between 1960 and 1995, 137 unique cases of Americanacquired myiasis were reported. Two of these $(1.5 \%)$ had a perineal infestation and one $(0.7 \%)$ was in the genitourinary tract. Our patient had many characteristics common to other reported cases but the site of infestation was unusual. This case also illustrated that the disadvantaged population at risk for HIV is also at risk for homelessness, substance abuse and their consequences.

When reached for follow-up, she was more concerned about the maggots than the HIV infection because of the stigma associated with myiasis.

Sherman (4) recommends that when maggots are present, one maggot should be submitted to the laboratory in alcohol or formaldehyde and at least one maggot should be submitted alive to facilitate species identification. Unfortunately, in this case, a live organism was not sent to the laboratory and we did not obtain a species identification.

Treatment should consist of thorough cleaning of the patient's wounds and attention to hygiene. For those with furuncular skin lesions, an occlusive ointment should be applied if the lesions are numerous. If this fails or if there is a solitary lesion, surgical removal can be effective (5). Antibiotics should only be prescribed for concurrent bacterial infections. Sherman (4) also suggests that mandatory reporting of myiasis would facilitate the collection of data and allow for a better epidemiological picture of the scope of the problem to be described. Making it notifiable could also assist in ensuring that these patients are offered the medical and social assistance that they require to meet their needs.

\section{REFERENCES}

1. Mandell GL, Bennett JE, Dolin R. Myiasis. In: Mandell GL, Douglas RG, Bennett JE, eds. Principles and Practice of Infectious Diseases.

Philadelphia: Churchill Livingstone, 2000:2976.

2. Zumpf F. Myiasis in Man and Animals in the Old World. London: Butterworth, 1965.

3. Greenberg B. Two cases of human myiasis caused by Phaenicia sericata (Diptera: Calliphoridae) in Chicago area hospitals. J Med Entomol 1984:21:615.

4. Sherman RA. Wound myiasis in urban and suburban United States. Arch Intern Med 2000;160:2004-14.

5. Safdar N, Young DK, Andes D. Autochthonous furuncular myiasis in the United States: Case report and literature review. Clin Infect Dis 2003;36:e73-80. 


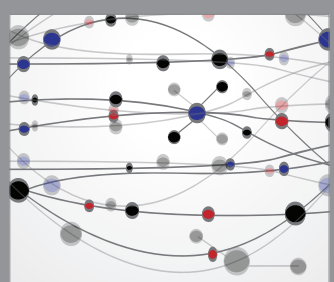

The Scientific World Journal
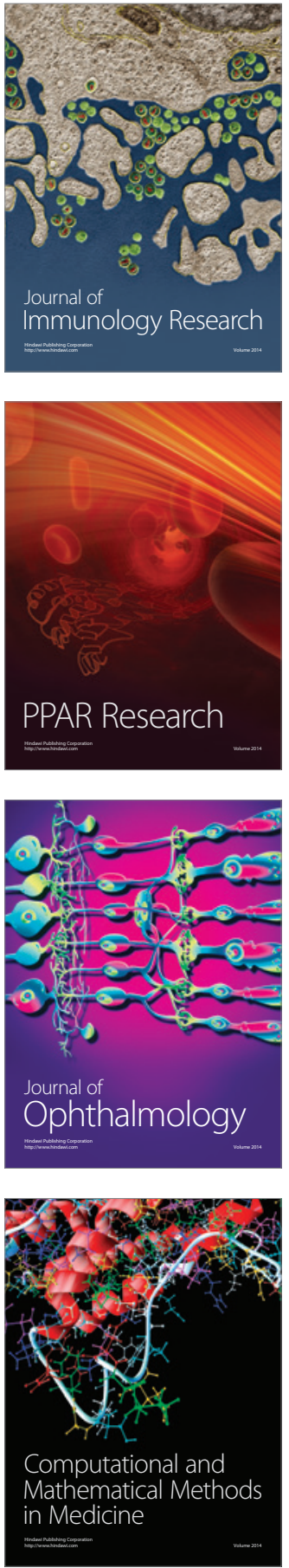

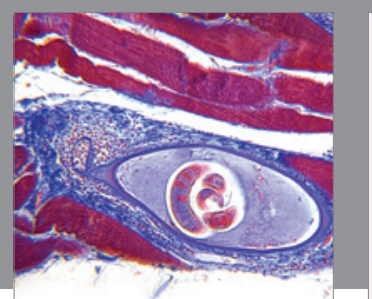

Gastroenterology Research and Practice

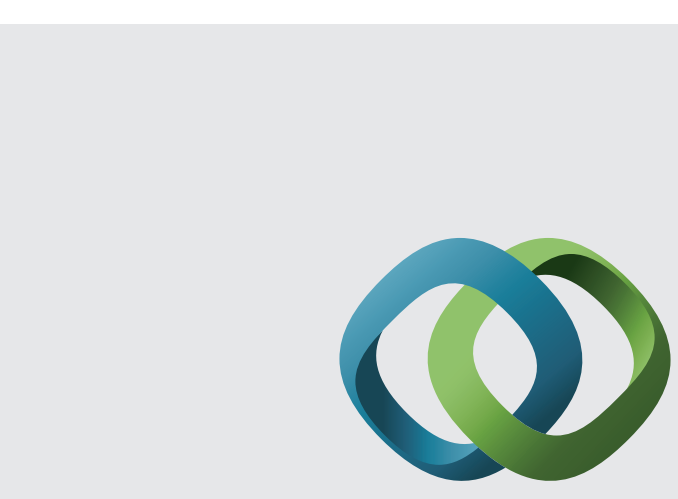

\section{Hindawi}

Submit your manuscripts at

http://www.hindawi.com
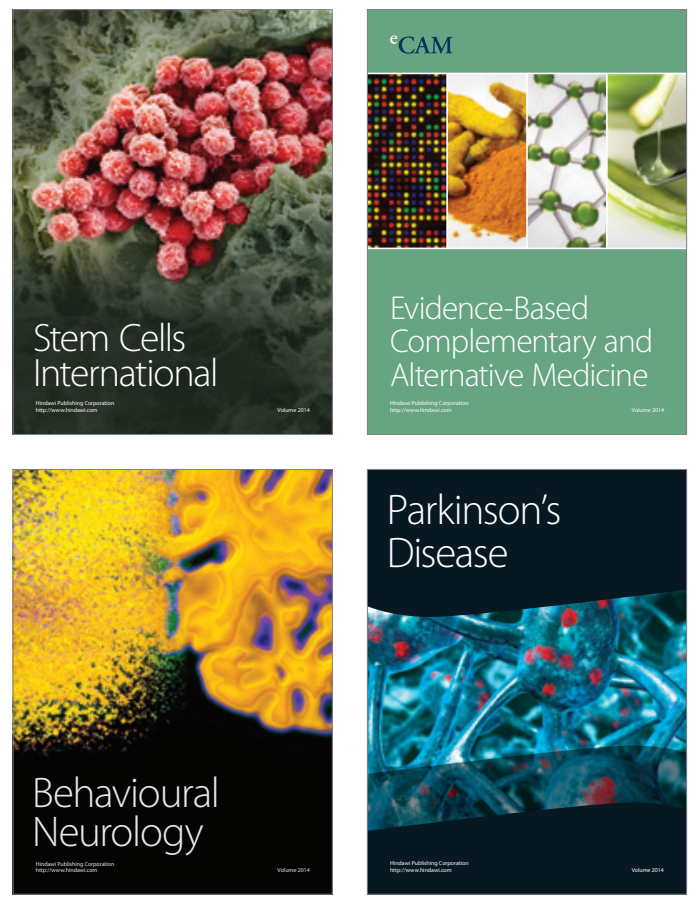
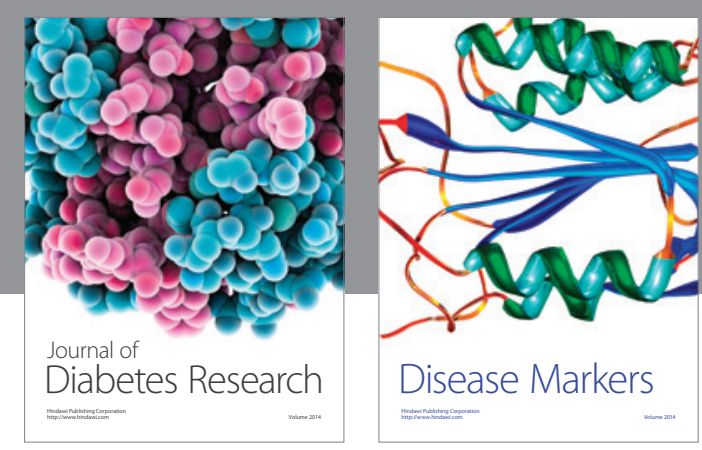

Disease Markers
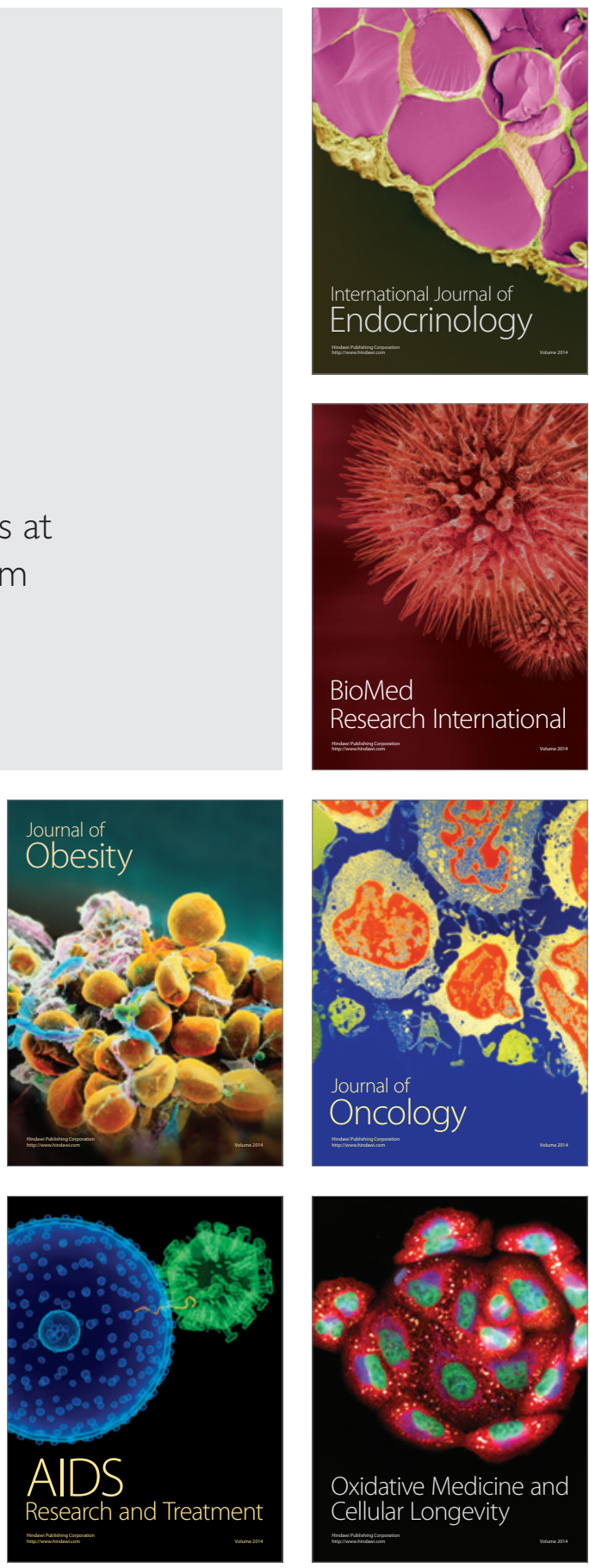